\title{
THE GENERAL DENTAL PRACTITIONER
}

\section{Volume 38}

April 2021

Council of the College of

General Dental Practitioners

of Sri Lanka 2020/202].

\author{
Dr. Malcolm Stanislaus \\ President
}

Professor B.G. Nanayakkara Immediate Past President

\section{Dr. Lionel Dassanayake Vice President}

\section{Dr. Sama Weerapperuma Secretary}

\section{Dr. Ravi Ranawaka Asst. Secretary}

\section{Dr. C.H. Chang \\ Treasurer}

\section{Dr. Hilary Cooray Editor}
Council Members Dr. Miraz Mukthar Dr.(Mrs) Kanthi Chang
Dr.Rifeth Rasheed
Dr. Ramesh Kanna

\section{Covid 19 - Pandemic - Challenges and Opportunities for General Dental Practitioners in the "new normal" Scenario.}

The World Health Organization declared Covid -19 as a pandemic in early March 2020. This was managed very effectively in the early stages due to the leadership of His Excellency the President assisted by the three forces, Ministry of Health and Police. The pandemic still rages on in Sri Lanka and in the World. It is likely that it will continue for another year or perhaps two years. The Dental profession needs to adapt itself strengthened to empower its members, its team and the stakeholders to co-exist with Covid -19 in a " New Normal " environment.

Covid -19 is very much spreading across the globe recording 128 Million reported cases and 2,890,000 deaths as at end of March 2021.

The Health authorities in the government engages in detection, isolation, testing and treating every case and trace every contact.

The Dental professionals in dental practice have adapted in many ways. Some practices have -

1. Closed not seeing any patients

2. Closed but seeing only emergencies.

3. Open but have lower patient volumes.

4. Open and have business as an usual.

The recommended guidelines to treat patients for emergency treatment or comprehensive dental treatment have to be maintained during and until the Covid-19 pandemic is declared as ended.

In General Dental Practices the patients are taken in after screening. A proper Medical and social history is recorded together with the temperature. Social distancing of 2 Meters is maintained.

The Dental team consisting of the receptionist, Dental Surgery Nurse aide and the Dental Surgeon need to have the recommended personal, protection equipment consisting of Masks, (KN 95 or FFP3) Face Shield, goggles and over garments. They should be recognized 
as a priority group and given the Covid Vaccine. These equipment cause to the team, discomfort, visual difficulties and also interferes with patient communication. Patient instructions especially tooth brushing demonstration are severely affected. The operational and cost maintaining a safe environment to the patient and the staff is formidable.

This is aggravated by the fact that the patient volumes have dropped. The financial stability of individual practices have been severely compromised. In some members of the dental team, the fear of oneself transmitting the infection to the family has gone too far so as to cause mental distress.

The dental trade organizations have suffered setbacks and losses due to wide ranging scenarios. Supply chains have been disrupted. The dental traders are facing issues such as less demand for items, expiry dates of products, delay in shipments, cash flow, and interest payments, value of stock in trade, contribute to their losses.

The dental practices does not work in isolation. The dental laboratory service which augments the dental prosthetic and orthodontic service also suffered similar predicaments. They too have to work with limited resources and even less income. In the field of continuing education of the profession, is restricted to on-line and zoom meetings. Foreign travel is almost done away with.

The cost of private sector treatments in General Dental Practice will essentially increase due to additional costs. The Covid-19 has not only imposed challenges but also given a wide range of opportunities for the General Dental Practitioners and the Dental team. Amongst them are continuing education programs, Post Graduate degree programs and other educational activities which can be conveniently accessed and done due to the availability of time. Some General Dental Practitioners opted to renovate their Surgery buildings,acquire and refurbish new premises, updating dental equipments and facilities.

This is a great opportunity to renew relationships with the members of their family especially devote more time and attention,to the spouse and children, who perhaps may have been neglected in the pre Covid era due to pressure of work. Still some others have given way to their life long ambitions in agriculture development, aquaculture and other hobbies they loved but could not engage in due to the lack of time. Some others caught up with their writing skills and had developed themselves as authors to publish books.

The New Normal, explicitly makes us realize that the Pre Covid day to day normal lifestyle is not possible until the Pandemic is fully controlled, not only in Sri Lanka but also globally. Hence there a great deal of adaptation we all have to adhere to in all our activities in order to minimize the risk of Covid 19 virus transmission and get on with our lives.

Editor - Dr. Hilary Cooray

$B D S$ ( Cey),MSc(Lond),MFGDP,RCS(UK),FICCDE(Ortho), Singapore 